\title{
The importance of daily removal of the denture biofilm for oral and systemic diseases prevention
}

\author{
Karin Hermana Neppelenbroek \\ Co-Editor-in-Chief - Journal of Applied Oral Science
}

\section{Dear Readers,}

Inadequate cleaning of removable dentures promotes the accumulation and adhesion of biofilm, which is one of the main causes of failure of these prostheses. Complete denture biofilm is defined as a dense layer of complex microbial communities embedded in a polymeric matrix, and it is known to contain more than 1011 microorganisms by gram in dry weight ${ }^{13}$. The composition of the denture biofilm microbial community is similar to that of dental biofilm with the exception of an increase in Candida spp $^{13}$.

It has been widely reported that denture biofilm acts as a reservoir for opportunistic microorganisms that can cause local infections, especially Candida-related denture stomatitis, or even systemic diseases ${ }^{1,3,8,15}$. Denture stomatitis is the most common form of oral candidal infection found on the palate of denture wearers (11 to $70 \%)^{3,18}$. About $93 \%$ of individuals with clinical signs of denture stomatitis present fungal infection, being Candida albicans the most prevalent species, identified in 50 to $98 \%$ of all cases ${ }^{2,18}$. Candida spp. interact with other microorganisms in the oral cavity, particularly Streptococcus spp. and Staphylococcus spp., thus resulting in a complex and mixed biofilm formation with organized structure that is difficult to remove ${ }^{2,18}$. Moreover, bacteria in acrylic biofilms resulted in higher virulence and pathogenicity of Candida biofilms 4 . Apart from local infections such as denture stomatitis, recent studies have recognized a relationship between denture biofilm and systemic diseases, mainly in elderly individuals ${ }^{8,15}$. Kashiwabara, et al. ${ }^{8}$ (2007) found high levels of Candida spp. and Staphylococcus spp. (including methicillin-resistant Staphylococcus aureus) from palatal tissue surface of maxillary dentures of geriatric inpatients and maxillary defective patients, respectively. It is know that respiratory pathogens preferentially colonize teeth or dentures, rather than soft tissue, being the pneumonia the leading cause of death attributable to infection in patients aged 65 years and older 5 . According to O'Donnell, et al. ${ }^{15}$ (2015), given a denture's close proximity to the respiratory tract, denture wearers are potentially at an increased risk of aspirating opportunistic pathogens from the denture into their lungs. These authors showed a high prevalence of putative respiratory pathogens on the dentures of ambulatory adults, a finding that could explain the source of infection in some cases of aspiration pneumonia ${ }^{16}$. Besides aspiration pneumonia, oral pathogens have been implicated in bacterial endocarditis, gastrointestinal infection and chronic obstructive pulmonary disease, among others, and dentures offer a reservoir for microorganisms associated with these infections ${ }^{5,8}$. Therefore, it is crucial that careful daily removal of the biofilm present in the oral cavity and on complete dentures is performed with adequate denture cleansing in order to prevent associated oral and systemic diseases ${ }^{6}$.
Although most patients clean their dentures by manual brushing, this method when used isolated has been considered one of the least efficient for biofilm control ${ }^{12}$. The brushing method requires manual dexterity and visual acuity which are usually compromised in elderly individuals ${ }^{12}$. Furthermore, the microorganisms embedded in the biofilm become partially protected by the shear forces of the toothbrush ${ }^{2}$. The irregularities and porosities of acrylic bases also favor the penetration of microorganisms, which raise difficulties in cleaning them exclusively by brushing, and therefore the prostheses can become a source of infection and re-infection of supporting tissues ${ }^{12}$. Consequently, for biofilm control, daily immersion in cleaning solutions has been suggested to complement denture hygiene and this combination has demonstrated greater results when compared to brushing alone ${ }^{10}$.

Various denture cleansers are commercially available with different active agents, including hypochlorite, peroxides, enzymes and acids. Homemade solutions are often adopted by patients who perform a daily chemical method of denture cleaning because of their easy of acquisition and low cost. Sodium hypochlorite is a chemical solution that is routinely recommended for cleaning dentures and has the ability to dissolve mucin and other organic components being highly effective at removing light stains. Also, sodium hypochlorite solution has bactericidal and fungicide action $^{6}$. However, this chemical agent corrodes metal components of prostheses and degrades the acrylic resin components, causing color changes (lightening) and an increase in surface roughness ${ }^{6,11}$. Chlorhexidine also been suggested as an adjunct to denture cleansing by brushing. This chemical agent is widely used both for prevention and treatment of oral infections, as antiseptics and disinfectants for removable dentures ${ }^{3,7}$. Chlorhexidine gluconate presents wide spectrum of action and significant substantivity, hence it can be used effectively when mixed bacterial and fungal biofilms are present ${ }^{8}$. Alkaline peroxides are also commonly used as denture cleansers and produce an effervescent alkaline solution of hydrogen peroxide, containing active oxygen, when in contact with water. The effervescence presents a mechanical action for removing debris, and the oxygen has antimicrobial and stain-removing effects. Some products also contain enzymes to failure biofilm proteins ${ }^{10,14}$. Seeking an alternative to commonly known denture cleansers, new materials with antimicrobial action have been investigated such as the oil derived from castor bean (Ricinus communis) evaluated by Salles, et al. ${ }^{18}$ (2015) in this issue. R. communis oil solution presents biocompatibility and bactericidal and fungicidal effects. It is colorless and does not have an unpleasant smell. These characteristics along with detergent action make its use in denture cleaning possible ${ }^{9}$.

As control of biofilm is a constant concern, in vivo and in vitro studies ${ }^{10,16,18,19}$ have been continuously 
developed to evaluate the efficiency of cleaning agents for dentures. Pellizzaro, et al. ${ }^{16}$ (2012) investigated in vitro the effectiveness of combining brushing and cleansing agents (dentifrice, $2 \%$ chlorhexidine gluconate, $1 \%$ sodium hypochlorite and abrasive-free foaming antibacterial denture cleanser - Polident fresh cleanse ${ }^{\circledR}$ ) in killing C. albicans biofilm on acrylic resin disks. They concluded that the use of the combined method of brushing with cleansing agents is an effective method to reduce $\mathrm{C}$. albicans biofilm, being $2 \%$ chlorhexidine gluconate and $1 \%$ sodium hypochlorite the most effective solutions. The aim of the study by de Sousa Porta, et al. ${ }^{19}$ (2015) was to evaluate, in vivo, the efficacy of $0.5 \%$ sodium hypochlorite for 3 min over 90 days as a denture cleanser and its effect on color stability and surface roughness of complete dentures. Patient satisfaction with the denture cleaning method was also assessed. The authors found that $0.5 \%$ sodium hypochlorite solution in conjunction with brushing was effective in reducing microorganism numbers without causing significant color or roughness changes. Moreover, participants reported high levels of satisfaction with the cleaning results. Lucena-Ferreira, et al. ${ }^{10}$ (2014) investigated in vitro the effect of daily exposure for $3 \mathrm{~min}$ in an alkaline peroxide enzymecontaining commercial denture cleanser (Polident ${ }^{\circledR} 3$ Minute) on a multispecies biofilm (five bacteria and Candida albicans) formed on cylindrical specimens of acrylic resin. The daily exposure of multispecies biofilms to denture cleanser reduced the number of total microorganisms but increased C. albicans counts. Thus, the authors suggested that daily use of denture cleanser is an effective method for controlling bacteria in biofilm, but it can potentially select C. albicans, an important etiological agent of oral candidosis. In this issue, Salles, et al. ${ }^{18}$ (2015), by a crossover randomized clinical trial, aimed to evaluate the antimicrobial activity of sodium hypochlorite $(0.25 \%$ and $0.5 \%$ ) and $R$. communis oil $(10 \%)$ solutions along with the mechanical method of brushing against Streptococcus mutans, Candida spp., and Gramnegative microorganisms. All three solutions showed antimicrobial activity against $\mathrm{S}$. mutans. For Candida spp., R. communis oil and $0.25 \%$ sodium hypochlorite solutions showed similar effect while $0.5 \%$ sodium hypochlorite showed superior activity. Both sodium hypochlorite solutions showed antimicrobial action against gram-negative microorganisms. The Candida species most frequently isolated was C. albicans, followed by C. tropicalis and C. glabrata. The authors concluded $0.5 \%$ sodium hypochlorite solution was the most effective and might be used for short immersions along with brushing to control denture biofilm formation. As R. communis demonstrated antimicrobial activity against $\mathrm{S}$. mutans and Candida spp., this solution also was recommended as an auxiliary method of denture cleaning along with brushing ${ }^{18}$.

Adoption of routine oral hygiene practices including mechanical cleaning in conjunction with immersion in denture cleansers is essential to ensure the careful daily removal of oral and denture biofilms. This is the key to minimize the risk of opportunistic infections, to contribute to good oral and overall systemic health and to maintain an aesthetically pleasing, odor-free appliance. More than being able to recommend a certain denture cleanser, the clinician should advise patients on the importance of removing the denture biofilm for the maintenance of oral and general health as well instruct the denture wearers to use the denture cleanser it correctly as co-adjuvant method for denture cleaning.

\section{REFERENCES}

1- André RF, Andrade IM, Silva-Lovato $\mathrm{CH}$, Paranhos HF, Pimenta FC, Ito IY. Prevalence of mutans streptococci isolated from complete dentures and their susceptibility to mouthrinses. Braz Dent J. 2011;22(1):62-7.

2- Baena-Monroy T, Moreno-Maldonado V, Franco-Martínez F, Aldape-Barrios B, Quindós G, Sánchez-Vargas LO. Candida albicans, Staphylococcus aureus and Streptococcus mutans colonization in patients wearing dental prosthesis. Med Oral Patol Oral Cir Bucal. 2005;10(Suppl 1):27-39.

3- Banting DW, Hill SA. Microwave disinfection of dentures for the treatment of oral candidiasis. Spec Care Dentist. 2001;21(1):4-8.

4- Cavalcanti YW, Morse DJ, Silva WJ, Del-Bel-Cury AA, Wei X, Wilson $M$, et al. Virulence and pathogenicity of Candida albicans is enhanced in biofilms containing oral bacteria. Biofouling. 2015;31(1):27-38.

5- Coulthwaite L, Verran J. Potential pathogenic aspects of denture plaque. Br J Biomed Sci. 2007;64(4):180-9.

6- Felton D, Cooper L, Duqum I, Minsley G, Guckes A, Haug S, et al. Evidence-based guidelines for the care and maintenance of complete dentures: a publication of the American College of Prosthodontists. J Prosthodont. 2011;20(Suppl 1):S1-S12.

7- Hennessey TS. Some antibacterial properties of chlorhexidine. J Periodontal Res Suppl. 1973;12:61-7.

8- Kashiwabara T, Yoshijima Y, Hongama S, Nagao K, Hirota K, Ichikawa $\mathrm{T}$. Denture plaque microflora in geriatric inpatients and maxillary defect Patients. Prosthodont Res Pract. 2007;6(3):153-8.

9- Laureano Filho JR, Andrade ES, Albergaria-Barbosa JR, Camargo IG, Garcia RR. Effects of demineralized bone matrix and a 'Ricinus communis' polymer on bone regeneration: a histological study in rabbit calvaria. $J$ Oral Sci. 2009;51:451-6.

10- Lucena-Ferreira SC, Ricomini-Filho AP, Silva WJ, Cury JA, Cury AA. Influence of daily immersion in denture cleanser on multispecies biofilm. Clin Oral Investig. 2014;18(9):2179-85.

11- Neppelenbroek KH, Kurokawa LA, Procópio AL, Pegoraro TA, Hotta J, Mello Lima JF, et al. Hardness and surface roughness of enamel and base layers of resin denture teeth after long-term repeated chemical disinfection. J Contemp Dent Pract. 2015;16(1):54-60.

12- Neppelenbroek KH, Pavarina AC, Palomari Spolidorio DM, Sgavioli Massucato EM, Spolidorio LC, Vergani CE. Effectiveness of microwave disinfection of complete dentures on the treatment of Candida-related denture stomatitis. J Oral Rehabil. 2008;35(11):836-46.

13- Nikawa H, Hamada T, Yamamoto T. Denture plaque - past and recent concerns. J Dent. 1998;26(4):299-304.

14- Nikawa H, Yamamoto T, Hamada T, Sadamori S, Agrawal S. Cleansing efficacy of commercial denture cleansers: ability to reduce Candida albicans biofilm. activity. Int J Prosthodont. 1995;8(6):527-34.

15- O'Donnell LE, Smith K, Williams C, Nile CJ, Lappin DF, Bradshaw D, et al. Dentures are a reservoir for respiratory pathogens. J Prosthodont. In press 2015 [cited 2015 Dec 11]. Available from: <http:dx.doi.org/ 10.1111/ jopr.12342>

16- Pellizzaro D, Polyzois G, Machado AL, Giampaolo ET, Sanitá PV, Vergani CE. Effectiveness of mechanical brushing with different denture cleansing agents in reducing in vitro Candida albicans biofilm viability. Braz Dent J. 2012;23(5):547-54.

17- Salerno C, Pascale M, Contaldo M, Esposito V, Busciolano M, Milillo $\mathrm{L}$, et al. Candida-associated denture stomatitis. Med Oral Patol Oral Cir Bucal. 2011;16(2):e139-43.

18- Salles MM, Badaró MM, Arruda CNF, Leite VMF, Silva CHL, Watanabe $\mathrm{E}$, et al. Antimicrobial activity of complete denture cleanser solutions based on sodium hypochlorite and Ricinus communis - a randomized clinical study. J Appl Oral Sci. 2015;23(6):637-42.

19- Sousa Porta SR, Lucena-Ferreira SC, Silva WJ, Del Bel Cury AA Evaluation of sodium hypochlorite as a denture cleanser: a clinical study. Gerodontology. 2015;32:260-6. 